\title{
The importance of adult couple relationships in primary care
}

Why should primary care practitioners be interested in the adult couple relationship, something that seems in-between the needs of individuals to have their care needs recognised and the needs of families to support parenting and protect and nurture healthy children? Aren't couple relationships best seen as a matter for the partners involved, rather than as a focus for interventions? The short answer is that a focus on the adult couple relationship can be one of the most effective ways of supporting and helping individuals, parents, and children. There is now a considerable body of evidence that points to the fundamental importance of adult couple relationships for a variety of physical and mental health outcomes for both adults and children. The evidence comes from a variety of sources: randomized controlled studies of therapies for specific disorders; naturalistic studies of the impacts of clinics that offer help to couples (Hewison et al., 2016); and communitybased epidemiological surveys that look at correlations and prevalence. Much comes from the study of marriages and some from committed relationships, whether gay or straight, but all highlight the interdependency of good relationships and well-being. ${ }^{1}$

\section{Couple relationships and adult mental health}

Whisman and Uebelacker (2003) have indicated that particular psychiatric disorders are more likely in people who are martially distressed as opposed to those who are not. In their large community survey in the United States they noted that people who live in distressed and troubled relationships are three times more likely to suffer from mood disorders, two and a half times more likely to suffer from anxiety disorders, and twice as likely to suffer from substance use disorders as non-martially distressed people.

\footnotetext{
${ }^{1}$ This Editorial draws on the extensive range of Briefings from Tavistock Relationships available at http://www.tavistockrelation ships.ac.uk/policy-research/policy-briefings

(C) Cambridge University Press 2017
}

They suggest that improving the quality of the couple relationship is of value in a range of cases where there are coexisting mental health disorders and relationship distress, saying that the treatment of relationship distress could alleviate up to $30 \%$ of cases of major depression (Whisman and Bruce, 1999). In the United Kingdom this has been taken up in the national health service with the National Institute for Health and Clinical Excellence recommendation of couple therapy as a suitable therapy for treating depression in Improving Access to Psychological Therapies services (Hewison et al., 2014). It is clear that depression and couple stress and conflict have bi-directional impacts on each other (Davila et al., 2003) and that individual treatments such as Cognitive Behavioural Therapy do not improve relationships even though they help depression. Treating only the individual means that the depression-aggravating relationship setting does not change, rendering individuals more likely to have a subsequent relapse including those who have already been successfully treated for depression (whether by individual psychotherapy or psychopharmacological treatments) (Whisman, 2001). In fact, relationship distress also has a detrimental impact on how well treatments work in the first place (Denton et al., 2010; Foran et al., 2015).

Research has also shown that within the family and close friendship network, it is the couple relationship that has the most impact on the prevalence of major depression (Whisman et al., 2000), and the longer the couple has been distressed, the stronger the link to depression (Kouros et al., 2008). Be et al.'s (2013) 23-year study of somatic symptoms and relationship disagreements showed that levels of each were elevated where there was depression as compared with families without a depressed spouse, and life satisfaction - especially for women - is impaired by relationship distress. This finding echoes other studies such as Beach et al. (2003) and the work of Cano and O'Leary (2000) showing that humiliating events for women in marital relationships (infidelities and threats of separation) are six times more likely to result in an episode of major depressive disorder than in a control group where 
there was not such humiliation. Beach et al. (2004) have shown that incidents of physical aggression aimed at wives in heterosexual relationships also unsurprisingly - increase the risk of subsequent depression.

Couple relationship distress can lead to a lowering of social and functional skills, in addition to depression, making it harder to recover (Segrin, 2000; Choi and Marks, 2008). Although this reduction in social skills is associated with depression, a 10-year-community study by Teo et al. (2013) showed that social isolation alone was not predictive of future incidents of depression, whereas poor quality of relationships with spouses, and to a lesser extent with family members - but not with friends - was predictive of future incidents of depression 10 years later. People with a lot of relationship strain were more than twice as likely to have an episode of major depression as those with little relationship strain. This effect occurred even if there had not been a prior history of depression, with difficulty in relation to a spouse or partner (not family members or friends) being significantly associated with future depression.

The good news is that treating relationship distress reduces subsequent health service usage by $22 \%$ (Law and Crane, 2000), with higher users (defined as having four or more visits within six months) reducing their usage of urgent care by $78 \%$ after receiving conjoint therapy (Law et al., 2003), underlining the importance of attending to the close relationships that people experiencing episodes of depression have. The London Depression study (Leff et al., 2000) indicated that couples preferred therapy to antidepressants, with only $15 \%$ of participants in the couple therapy arm dropping out of treatment as compared with $56.8 \%$ of those in the medication arm.

\section{Couple relationships and postnatal depression}

Both mothers and fathers can become postnatally depressed. The prevalence of postnatal depression in mothers is about $13 \%$ with a range of $3-25 \%$ of women (O'Hara and Swain, 1996), that of fathers is about $10.4 \%$, and the two are correlated (Paulson and Brazemore, 2010; Barlow and Coe, 2012). Depression in either partner is associated with worse outcomes for their children
(Murray and Cooper, 1996; Ramchandani et al., 2008) and depression in both partners is additionally associated with poorer adherence to good-parenting behaviours such as breastfeeding (Paulson et al., 2006). Although not all children grow up with both parents, the Millennium Cohort Study suggests that nearly all children $(>95 \%)$ are born into partnerships between parents, whether married or cohabiting (cited in Burgess, 2011: 6). It is clear that depressed new mothers turn to their partners for support more than anyone else including health professionals (Holopainen, 2002), and that such support is associated with both lower rates of depression (Cox et al., 2008) and shorter stays in hospital for mothers with pre- and post-birth psychiatric disorders (Grube, 2004). It makes sense to have the parents' couple relationship as an important focus when thinking about enabling the optimum family conditions for good child development.

\section{Couple relationships and children's mental health}

We have known for decades that particular kinds of conflict between couples who are parenting are damaging to children's mental and physical health (Towle, 1931; Emery, 1982; Grych and Fincham, 1990; Davies and Cummings, 1994; Harold and Conger, 1997; Cowan and Cowan, 2002; Harold and Leve, 2012). Ordinary difficulties and rows between couple which are managed by them and worked out are not harmful to children and are a model for how strong disagreements can be managed without resulting in the loss of love and affection (Cummings et al., 1991). Conflict which is frequent and intense, which never gets settled fully but just seems to chain together with the next argument, is very harmful; however, to children at all ages. Babies become agitated; under-5s respond by crying, acting out, freezing, or withdrawing from or intervening in the conflict; older children show a range of distress including anxiety, depression, aggression, hostility, anti-social behaviour, and perform worse academically than their ability level (Harold et al., 2007). Couple conflict doesn't just have to be violent or outwardly expressed: deliberate coldness and withdrawal also affects children who become at risk for long-term emotional and behavioural problems (Cummings and Davies, 1994; Amato, 2001). Conflict in which 
children feel blamed, responsible, or at risk of it turning onto them is the most damaging of all (Grych et al., 2003). Helping parents manage the way they express and resolve conflict is an important factor in preventing childhood distress and there is strong evidence that improving the couple relationship leads to improvements in parenting, in the parent-child relationship, and in children's outcomes even if these other domains were not specifically targeted in the intervention and the parents are separated (Das Eiden et al., 1995; Finger et al., 2009; Faircloth et al., 2011).

In addition, good relationships between the adult couple are associated with good relationships between the baby and the father in particular, helping to develop secure attachment styles in the infant (Frosch et al., 2000; Wong et al., 2009). The converse is also true: relationship conflict leads to less positive interactions between fathers and their babies, and less attachment security as a result (Owen and Cox., 1997); conflict between partners before birth seems to have a similar result (Yu et al., 2012).

\section{Couple relationships and physical health}

The couple relationship has an important impact on physical health and well-being too (Verbrugge, 1979; Office for National Statistics, 2011). The quality of the relationship affects self-perceptions of health and objective indicators of health status (Ren, 1997; Carels et al., 1998). It affects adjustment to health problems and has an impact on health outcomes, including earlier mortality (Hibbard and Pope, 1993; Rodrique and Park, 1996; Kiecolt-Glaser and Newton, 2001). Relationship quality also affects speed of recovery and likelihood of relapse. Whisman and Uebelacker point out:

'Taken together, the existing research suggests that people who are unhappy with their intimate relationships and have poor relationship functioning are not only more likely to have a mental or physical health problem, they are also less likely to respond to treatment for such a problem' (2003: 13).

They indicated that there is clear evidence that conditions such as:

- alcohol misuse in both male and female partners (Wilsnack et al., 1984; Romelsjo et al., 1991;
Orth-Gomér et al., 2000; Kiecolt-Glaser and Newton, 2001; Overbeek et al., 2006; Whisman et al., 2006; Levitt and Cooper, 2010);

- cardiovascular disease (Coyne et al., 2001; Baker et al., 2003; Gallo et al., 2003; Grewen et al., 2005; Holt-Lunstad et al., 2008; King and Reis, 2011);

- diabetes (Trief et al., 2001; Fisher et al., 2004; Trief et al., 2006); and

- metabolic syndrome (Whisman et al., 2010; Whisman and Sbarra, 2012; Whisman and Uebelacker, 2012).

are linked to the quality of the couple relationship.

\section{Conclusion}

Primary care practitioners should 'think couple'. The quality of the adult couple relationship has an important part to play in the prevention, development, treatment, recovery, and relapse-prevention of a range of major mental and physical illnesses in adults and in their children. Attending to the couple relationship should be a more mainstream activity than it is currently, because of the potential benefits for individuals, couples, and families, as well as for the management and effective delivery of scarce health resources.

\section{David Hewison Head of Research, Tavistock Relationships London, UK}

\section{References}

Amato, P.R. 2001: Children of divorce in the 1990s: an update of the Amato and Keith (1991) meta-analysis. Journal of Family Psychology 15, 355-70.

Baker, B., Szalai, J.P., Paquette, M. and Tobe, S. 2003: Marital support, spousal contact and the course of mild hypertension. Journal of Psychosomatic Research 55, 229-33.

Barlow, J. and Coe, C. 2012: Family action perinatal support project. Research Findings Report Coventry, University of Warwick. Retrieved 12 September 2012 from http://www. family-action.org.uk/uploads/documents/Perinatal\%20Support \%20Project_Evaluation\%202012.pdf.

Be, D., Whisman, M.A. and Uebelacker, L.A. 2013: Prospective associations between marital adjustment and life satisfaction. Personal Relationships 20, 728-39.

Beach, S.R.H., Katz, J., Kim, S. and Brody, G.H. 2003: Prospective effects of marital satisfaction on depressive symptoms in established marriages: a dyadic model. Journal of Social and Personal Relationships 20, 355-71. 
Beach, S.R.H., Kim, S., Cercone-Keeney, J., Gupta, M., Arias, I. and Brody, G.H. 2004: Physical aggression and depressive symptoms: gender asymmetry in effects? Journal of Social and Personal Relationships 21, 341-60.

Burgess, A. 2011: Fathers' roles in perinatal mental health: causes, interactions and effects. Parenting UK News Bulletin, December, pp. 5-7.

Cano, A. and O'Leary, K.D. 2000: Infidelity and separations precipitate major depressive episodes and symptoms of non-specific depression and anxiety. Journal of Consulting and Clinical Psychology 68, 774-81.

Carels, R.A., Sczczepanski, R., Blumenthal, J.A. and Sherwood, A. 1998: Blood pressure reactivity and marital distress in employed women. Psychosomatic Medicine 60, 639-43.

Choi, H. and Marks, N.F. 2008: Marital conflict, depressive symptoms, and functional impairment. Journal of Marriage and Family 70, 377-90.

Cowan, P. and Cowan, C.P. 2002: Interventions as tests of family systems theories: marital and family relationships in children's development and psychopathology. Development and Psychopathology 14, 731-59.

Cox, J.E., Buman, M., Valenzuela, J., Joseph, N.P., Mitchell, A. and Woods, E.R. 2008: Depression, parenting attributes, and social support among adolescent mothers attending a teen tot program. Journal of Pediatric and Adolescent Gynecology 21, 275-81.

Coyne, J.C., Rohrbaugh, M.J., Shoham, V., Sonnega, J.S., Nicklas, J.M. and Cranford, J.A. 2001: Prognostic importance of marital quality for survival of congestive heart failure. American Journal of Cardiology 88, 526-29.

Cummings, E.M., Ballard, M., El-Sheikh, M. and Lake, M. 1991: Resolution and children's responses to interadult anger. Developmental Psychology 27, 462-70.

Cummings, E.M. and Davies, P.T. 1994: Children and marital conflict: the impact of family dispute and resolution. New York: Guilford.

Das Eiden, R., Teti, D.M. and Corns, K.M. 1995: Maternal working models of attachment, marital adjustment, and the parent-child relationship. Child Development 66, 1504-518.

Davies, P.T. and Cummings, E.M. 1994: Marital conflict and child adjustment: an emotional security hypothesis. Psychological Bulletin 116, 387-411.

Davila, J., Karney, B.R., Hall, T.W. and Bradbury, T.N. 2003: Depressive symptoms and marital satisfaction: withinsubject associations and the moderating effects of gender and neuroticism. Journal of Family Psychology 17, 557-70.

Denton, W., Carmody, T., Rush, A., Thase, M., Trivedi, M., Arnow, B., Klein, D.N. and Keller, M.B. 2010: Dyadic discord at baseline is associated with lack of remission in the acute treatment of chronic depression. Psychological Medicine 40, 415-24.

Emery, R.E. 1982: Interparental conflict and the children of discord and divorce. Psychological Bulletin 92, 310-30.

Faircloth, W.B., Schermerhorn, A.C., Mitchell, P.M., Cummings, J.S. and Cummings, E.M. 2011: Testing the

Primary Health Care Research \& Development 2017; 18: 405-410 long-term efficacy of a prevention program for improving marital conflict in community families. Journal of Applied Developmental Psychology 32, 189-97.

Finger, B., Hans, S.L., Bernstein, V.J. and Cox, S.M. 2009: Parent relationship quality and infant-mother attachment. Attachment and Human Development 11, 285-306.

Fisher, L., Chesla, C., Chun, K., Skaff, M., Mullan, J., Kanter, R. and Gardiner, P. 2004: Patient-appraised couple emotion management and disease management among Chinese American patients with type 2 diabetes. Journal of Family Psychology 18, 302-10.

Foran, H.M., Whisman, M.A. and Beach, S.R.H. 2015: Intimate partner relationship distress in the DSM-5. Family Process 54, 48-63.

Frosch, C., Mangelsdorf, S. and McHale, J. 2000: Marital behaviour and the security of preschooler-parent attachment relationships. Journal of Family Psychology 14, 144-61.

Gallo, L.C., Troxel, W.M., Kuller, L.H., Sutton-Tyrrell, K., Edmundowicz, D. and Matthews, K.A. 2003: Marital status, marital quality, and atherosclerotic burden in postmenopausal women. Psychosomatic Medicine 65, 952-62.

Grewen, K.M., Girdler, S.S. and Light, K.C. 2005: Relationship quality: effects on ambulatory blood pressure and negative affect in a biracial sample of men and women. Clinical Methods and Pathophysiology 10, 117-24.

Grube, M. 2004: Pre- and postpartal psychiatric disorders and support from male partners. A first qualitative approximation. Nervenarzt 75, 483-88.

Grych, J.H. and Fincham, F.D. 1990: Marital conflict and children's adjustment: a cognitive-contextual framework. Psychological Bulletin 108, 267-90.

Grych, J.H., Harold, G.T. and Miles, C.J. 2003: A prospective investigation of appraisals as mediators of the link between interparental conflict and child adjustment. Child Development 74, 1176-193.

Harold, G.T., Aitken, J.J. and Shelton, K.H. 2007: Interparental conflict and children's academic attainment: a longitudinal analysis. Journal of Child Psychology and Psychiatry 48, 1223-232.

Harold, G.T. and Conger, R. 1997: Marital conflict and adolescent distress: the role of adolescent awareness. Child Development 68, 333-50.

Harold, G.T. and Leve, L. 2012: Parents and partners: how the parental relationship affects children's psychological development. In Balfour, A., Morgan, M. and Vincent, C., editors How couple relationships shape our world: clinical practice, research and policy perspectives. Chapter 2. London: Karnac, 25-55.

Hewison, D., Casey, P. and Mwamba, N. 2016: The effectiveness of couple therapy: outcomes in a naturalistic United Kingdom setting. Psychotherapy 53, 377-87.

Hewison, D., Clulow, C. and Drake, H. 2014: Couple therapy for depression: a clinician's guide to integrative practice. Oxford: Oxford University Press.

Hibbard, J.H. and Pope, C.R. 1993: The quality of social roles as predictors of morbidity and mortality. Social Science and Medicine 36, 217-25. 
Holopainen, D. 2002: The experience of seeking help for postnatal depression. Australian Journal of Advanced Nursing 19, 39-44.

Holt-Lunstad, J., Birmingham, W. and Jones, B.Q. 2008: Is there something unique about marriage? The relative impact of marital status, relationship quality, and network social support on ambulatory blood pressure and mental health. Annals of Behavioral Medicine 35, 239-44.

Kiecolt-Glaser, J.K. and Newton, T.L. 2001: Marriage and health: his and hers. Psychological Bulletin 10, 117-24.

King, K.B. and Reis, H.T. 2011: Marriage and long-term survival after coronary artery bypass grafting. Health Psychology 31, 55-62.

Kouros, C.D., Papp, L.M. and Cummings, E.M. 2008: Interrelations and moderators of longitudinal links between marital satisfaction and depressive symptoms among couples in established relationships. Journal of Family Psychology 22, 667-77.

Law, D.D. and Crane, D.R. 2000: The influence of marital and family therapy on health care utilization in a healthmaintenance organization. Journal of Marital and Family Therapy 26, 281-91.

Law, D.D., Crane, D.R. and Berge, J.M. 2003: The influence of marital and family therapy on high utilizers of health care. Journal of Marital and Family Therapy 29, 353-63.

Leff, J., Vearnals, S., Brewin, C.R., Wolff, G., Alexander, B., Asen, E., Dayson, D., Jones, E., Chisholm, D. and Everitt, B. 2000: The London depression intervention trial - randomised controlled trial of antidepressants $\mathrm{v}$. couple therapy in the treatment and maintenance of people with depression living with a partner: clinical outcome and costs. British Journal of Psychiatry 177, 95-100.

Levitt, A. and Cooper, M. 2010: Daily alcohol use and romantic relationship functioning: evidence of bidirectional, gender-, and context-specific effects. Personality and Social Psychology Bulletin 36, 1706-722.

Murray, L. and Cooper, P.J. 1996: The impact of postpartum depression on child development. International Review of Psychiatry 8, 55-63.

Office for National Statistics 2011: Initial investigation into subjective wellbeing from the opinions survey. Retrieved 24 March 2016 from http://www.ons.gov.uk/ons/dcp171776_ 244488.pdf.

O'Hara, M.W. and Swain, A.M. 1996: Rates and risk of postpartum depression - a meta-analysis. International Review of Psychiatry 8, 37-54.

Orth-Gomér, K., Wamala, S.P., Horsten, M., SchenckGustafsson, K., Schneiderman, N. and Mittleman, M.A. 2000: Marital stress worsens prognosis in women with coronary heart disease: the Stockholm Female Coronary Risk Study. Journal of the American Medical Association 295, 1289-290.

Overbeek, G., Vollebergh, W., de Graaf, R., Scholte, R., de Kemp, R. and Engels, R. 2006: Longitudinal associations of marital quality and marital dissolution with the incidence of DSM-III-R disorders. Journal of Family Psychology 20, 284-91.
Owen., M.T. and Cox, M.J. 1997: Marital conflict and the development of infant-parent attachment relationships. Journal of Family Psychology 11, 152-64.

Paulson, J.F. and Brazemore, S.D. 2010: Prenatal and postpartum depression in fathers and its association with maternal depression. A meta-analysis. Journal of the American Medical Association 303, 1961-969.

Paulson, J.F., Dauber, S. and Leiferman, J.A. 2006: Individual and combined effects of postpartum depression in mothers and fathers on parenting behavior. Pediatrics 118, 659-68.

Ramchandani, P.G., O'Connor, T.G., Evans, J., Heron, J., Murray, L. and Stein, A. 2008: The effects of pre- and postnatal depression in fathers: a natural experiment comparing the effects of exposure to depression on offspring. Journal of Child Psychology and Psychiatry 49, 1069-78.

Ren, X.S. 1997: Marital status and quality of relationships: the impact on health perception. Social Science and Medicine 44, 241-49.

Rodrique, J.R. and Park, T.L. 1996: General and illness-specific adjustment to cancer: relationship to marital status and marital quality. Journal of Psychosomatic Research 40, 29-36.

Romelsjo, A., Lazarus, N., Kaplan, G. and Cohen, R.D. 1991: The relationship between stressful life situations and changes in alcohol consumption in a general population sample. British Journal of Addiction 86, 157-69.

Segrin, C. 2000: Social skills deficits associated with depression. Clinical Psychology Review 20, 379-403.

Teo, A.R., Choi, H. and Valenstein, M. 2013: Social relationships and depression: ten-year follow-up from a nationally representative study. PLoS One 8, e62396.

Towle, C. 1931: The evaluation and management of marital status in foster homes. American Journal of Orthopsychiatry $1,271-84$.

Trief, P., Himes, C., Orendorff, R. and Weinstock, R. 2001: The marital relationship and psychosocial adaptation and glycemic control of individuals with diabetes. Diabetes Care 24, 1384-389.

Trief, P., Morin, P., Izquierdo, R., Teresi, J., Starren, J., Shea, S. and Weinstock, R. 2006: Marital quality and diabetes outcomes: the IDEATel project. Families, Systems, \& Health 24, 318-31.

Verbrugge, L. 1979: Marital status and health. Journal of Marriage and the Family 41, 267-85.

Whisman, M.A. 2001: The association between depression and marital dissatisfaction. In Beach, S.R.H., editor Marital and family processes in depression: a scientific foundation for clinical practice. Chapter 1 Washington, DC: American Psychological Association, 3-24.

Whisman, M.A. and Bruce, M.L. 1999: Marital dissatisfaction and incidence of major depressive episode in a community sample. Journal of Abnormal Psychology 108, 674-78.

Whisman, M.A. and Sbarra, D.A. 2012: Marital adjustment and interleukin-6 (IL-6). Journal of Family Psychology 26, 290-95. 
Whisman, M.A., Sheldon, C.T. and Goering, P. 2000: Psychiatric disorders and dissatisfaction with social relationships: does type of relationship matter? Journal of Abnormal Psychology 109, 803-8.

Whisman, M.A. and Uebelacker, L.A. 2003: Comorbidity of relationship distress and mental and physical health problems. In Snyder, D.K. and Whisman, M.A., editors, Treating difficult couples: helping clients with coexisting mental and relationship difficulties. Chapter 1 New York: Guilford Press, 3-26.

Whisman, M.A. and Uebelacker, L.A. 2012: A longitudinal investigation of marital adjustment as a risk factor for metabolic syndrome. Health Psychology 31, 80-86.

Whisman, M.A., Uebelacker, L.A. and Bruce, M.L. 2006: Longitudinal association between marital dissatisfaction and alcohol use disorders in a community sample. Journal of Family Psychology 20, 164-67.
Whisman, M.A., Uebelacker, L.A. and Settles, T.D. 2010: Marital distress and the metabolic syndrome: linking social functioning with physical health. Journal of Family Psychology 24, 367-70.

Wilsnack, R., Wilsnack, C. and Klassen, A. 1984: Women's drinking and drinking problems: patterns from a 1981 National Survey. American Journal of Public Health 74, 1231-238.

Wong, M.S., Mangelsdorf, S.C., Brown, G.L., Neff, C. and Schoppe-Sullivan, S.J. 2009: Parental beliefs, infant temperament, and marital quality: associations with infantmother and infant-father attachment. Journal of Family Psychology 23, 828-38.

Yu, C., Hung, C., Chan, T., Yeh, C. and Lai, C. 2012: Prenatal predictors for father-infant attachment after childbirth. Journal of Clinical Nursing 21, 1577-583. 